\title{
ATIVIDADE DE UREASE NO SOLO COM FEIJOEIRO INFLUENCIADA PELA COBERTURA VEGETAL E SISTEMAS DE PLANTIO(1)
}

\author{
Anna Cristina Lanna ${ }^{(2)}$, Pedro Marques da Silveira ${ }^{(2)}$, Mozaniel \\ Batista da Silva ${ }^{(3)}$, Tatiana Maris Ferraresi ${ }^{(4)} \&$ Huberto José \\ Kliemann $^{(5)}$
}

RESUMO

A urease é a enzima que catalisa a hidrólise da ureia em dióxido de carbono e amônia. A distribuição da urease e os fatores que a influenciam têm importância relevante em vista do uso da ureia na agricultura. Nesse sentido, este estudo teve como objetivo definir a época adequada de coleta de solo, após adubação nitrogenada no feijoeiro comum, para medir a atividade de urease e seu perfil, considerando os efeitos residuais de diferentes plantas de cobertura e de sistema de preparo do solo. O experimento foi instalado em um Latossolo Vermelho distrófico e o feijoeiro, cultivar BRS Valente, semeado em junho de 2005, em sucessão a quatro plantas de cobertura de solo: capim-mombaça, milho em consórcio com braquiária, sorgo granífero e estilosantes, e dois sistemas de cultivo, direto e convencional. $\mathrm{O}$ delineamento experimental foi o de blocos ao acaso em parcelas divididas. As amostras de solo foram coletadas aos 3, 6, 8, 10 e 12 dias após a aplicação da ureia em cobertura no feijoeiro. A maior atividade de urease no solo ocorreu quando o feijoeiro foi cultivado após capim-mombaça, independentemente do preparo do solo e da época de sua avaliação. A mobilização do solo em cultivo no sistema plantio direto determinou menor atividade de urease, independentemente das espécies de cobertura e das épocas de sua avaliação. O pico de atividade de urease ocorreu entre o sétimo e o oitavo dia após a aplicação de ureia, independentemente das espécies de cobertura e do preparo do solo sob cultivo irrigado do feijoeiro comum.

Termos de indexação: atributo bioquímico, perfil ureolítico, sistema plantio direto, plantio convencional, plantas de cobertura de solo.

\footnotetext{
(1) Recebido para publicação em outubro de 2008 e aprovado em setembro de 2010.

(2) Pesquisador, Embrapa Arroz e Feijão. Caixa Postal 179, CEP 75375-000 Santo Antônio de Goiás (GO). E-mails: aclanna@cnpaf.embrapa.br; pmarques@cnpaf.embrapa.br

(3) Engenheiro-Agrônomo, Fundação de Ensino Superior de Rio Verde, Caixa Postal 104, CEP 75900-000 Rio Verde, (GO). Email: mozaniel@fesurv.br

(4) Analista, Embrapa Arroz e Feijão. E-mail: tatiana@cnpaf.embrapa.br

(5) Professor, Universidade Federal de Goiás - Escola de Agronomia. Caixa Postal 131, CEP 74001-970 Goiânia (GO). E-mail: kliemann@agro.ufg.br
} 


\title{
SUMMARY: UREASE ACTIVITY AS INFLUENCED BY PLANTING SYSTEM AND PLANT COVER IN SOIL UNDER COMMON BEAN
}

\begin{abstract}
Urease is an enzyme that hydrolysis urea in carbon dioxide and ammonia. Urease distribution and influencing factors are highly relevant for the use of urea in agriculture. In this context, the purpose of this study was to verify the adequate time of soil sampling to measure urease activity, after $N$ application to common bean as related to different soil tillage systems and cover plant species. The experiment was conducted on a dystrophic Dark Red Latosol where common bean cultivar Valente was planted on June 2005 in succession of four cover plants: mombassa grass (Panicum maximum cv. Mombassa), corn/brachiaria association (Brachiaria brizantha $c v$. Marandu), grain sorghum (Sorghum bicolor (L.) Moench), and stylosanthes (Stylosanthes guianensis cv. Mineirão). Two soil tillage methods were studied, direct sowing and conventional tillage. The experiment was arranged in a random block design in split-split-plots. Soil samples were collected 3, 6, 8, 10, and 12 days after urea application as topdressing. The highest activity of urease in soil occurred when common bean was grown after Panicum maximum, regardless of the tillage system and time of evaluation. Due to the degree of soil mobilization urease activity was lowest under no-tillage, irrespective of the cover crops and time of evaluation. Urease activity peaked between the seventh and eighth day after application, regardless of cover crops and soil tillage system under irrigated common bean.
\end{abstract}

Index terms: biochemical properties, ureolitic profile, direct sowing system, conventional sowing system, soil plant cover.

\section{INTRODUÇÃO}

No Cerrado, os sistemas agrícolas usados pelos agricultores irrigantes incluem o feijoeiro no inverno em sucessão a milho, soja, arroz e a integração lavoura-pecuária. Essas rotações de culturas têm sido vistas como opções economicamente viáveis para manter uma produção sustentável. Além da rotação de culturas, o sistema plantio direto (SPD) tem sido uma das melhores alternativas para a manutenção da sustentabilidade dos recursos naturais na utilização agrícola dos solos. Esse sistema é um método conservacionista de manejo do solo, uma vez que se perde menos solo, água e nutrientes por erosão em relação ao sistema de plantio convencional (Oliveira et al., 2002). Esse sistema de manejo do solo oferece a possibilidade de uma cobertura do solo ininterrupta por plantas em crescimento ou restos vegetais, protegendo-o dos impactos negativos. Uma cobertura adequada de solo, geralmente, é obtida pela rotação de culturas e inclusão de espécies de adubos verdes produtoras de massa vegetal abundante (Silva, 2001).

Um dos principais fatores que devem ser considerados no SPD é a decomposição de resíduos das plantas de cobertura do solo, visto que podem ser consideradas como fontes de nutrientes minerais, essenciais ao crescimento e desenvolvimento das plantas: destaca-se, nesse cenário, o N, que é o mais exigido pelas culturas e um dos nutrientes com dinâmica mais complexa no sistema (D'Andrea et al., 2004).

Considerando o sistema solo-planta-atmosfera, a quantidade mais significativa de $\mathrm{N}$ é proveniente da atmosfera, ademais, de todos os elementos que circulam nesse sistema, é o que sofre maior número de transformações bioquímicas no solo (Moreira \& Siqueira, 2006). Além disso, devido ao alto dinamismo do $\mathrm{N}$ na natureza, esse nutriente está sujeito a perdas, que facilmente alcançam índices superiores a $80 \%$. Essas perdas, no ambiente solo, são ocasionadas principalmente por remoção pelas culturas, volatilização, imobilização biológica, erosão e lixiviação (Lara Cabezas \& Trivelin, 1990).

Uma vez que a grande maioria do $\mathrm{N}$ no solo apresenta-se em estruturas orgânicas, diversas hidrolases amídicas estão envolvidas na hidrólise do N orgânico adicionado ou nativo dos solos. Entre elas, as mais importantes são L-asparaginase, Lglutaminase, amidase e urease. Esta última (ureia amido-hidrolase - EC 3.5.1.5) é a enzima que catalisa a hidrólise de ureia (composto orgânico) a $\mathrm{CO}_{2} \mathrm{e} \mathrm{NH}_{3}$, sendo amplamente distribuída na natureza (Kandeler \& Gerber, 1988). A velocidade da hidrólise da ureia é influenciada pelo tipo de vegetação, bem como a quantidade aplicada. A intensidade do efeito da matéria orgânica na atividade da urease dependerá da sua disponibilidade como fonte energética para os microrganismos e também da facilidade de decomposição microbiana da matéria orgânica (Dick et al., 1996; Santos \& Camargo, 1999). A análise da atividade de urease no solo pode fornecer uma indicação do potencial do solo em converter $\mathrm{N}$ orgânico em mineral, dando início ao processo de mineralização do N. A amônia, o principal produto da hidrólise da urease, pode ter vários destinos, de acordo com as condições ambientais, sendo o $\mathrm{N}$ possível de ser imobilizado pelos microrganismos, absorvido pelos 
vegetais superiores, adsorvido pelos minerais de argila, além de ser oxidado a nitrato, iniciando assim o processo de nitrificação (Victoria et al., 1992).

A urease é uma enzima extracelular produzida por bactérias, actinomicetos e fungos do solo ou, ainda, originada de restos vegetais (Reynolds et al., 1987). Sua atividade é aparentemente ótima em pH 8,5 a 9,0 (Tabatabai \& Bremner, 1972), e os valores de Km aparente para ureia situam-se na faixa de 1,1 a 3,4 $\mathrm{mmol} \mathrm{L}^{-1}$ (Tabatabai, 1994).

A maioria dos solos de Cerrado onde o feijoeiro comum é cultivado são ácidos e de baixa fertilidade natural, necessitando de algum tipo de adubação (mineral ou orgânica). Para suprir a carência de $\mathrm{N}$ no seu cultivo em momentos de elevada demanda pela planta, há necessidade de sua disponibilidade imediata, visto que se trata de uma planta de ciclo curto, exigente nesse nutriente. Dessa forma, utiliza-se, em larga escala, a ureia como fertilizante nitrogenado, para não limitar a produtividade (Silva \& Silveira, 2000). No entanto, tem-se verificado, ocasionalmente, baixo aproveitamento do $\mathrm{N}$ dessa fonte (ureia) pelas culturas, o que se deve, entre outros fatores, à volatilização de amônia. No solo, a ureia é rapidamente decomposta, alterando a utilização desse importante fertilizante nitrogenado pelas plantas, com taxa de recuperação de $\mathrm{N}$ do fertilizante inferior a $50 \%$ (Byrnes, 2000).

Este estudo objetivou avaliar a atividade da urease em solo cultivado com feijoeiro comum em função da presença de restos culturais de plantas de cobertura, sistemas de plantio e dias após a aplicação de ureia no solo.

\section{MATERIAL E MÉTODOS}

O experimento foi conduzido na Fazenda Capivara, da Embrapa Arroz e Feijão, localizada no município de Santo Antônio de Goiás, GO, em Latossolo Vermelho distrófico de textura argilosa. O estudo iniciou-se com o plantio direto, em novembro de 2004, das culturas de cobertura: capim-mombaça (Panicum maximum cv. Mombaça), milho (Zea mays L.) em consórcio com braquiária (Brachiaria brizantha cv. Marandu), sorgo granífero (Sorghum bicolor (L.) Moench) e estilosantes (Stylosanthes guianensis cv. Mineirão). Essas espécies foram cultivadas na área experimental, anualmente, durante o verão, desde 2001, de modo que o cultivo de 2004 correspondeu ao quarto cultivo dessas culturas na área. A adubação anual no estabelecimento dessas espécies foi feita com $400 \mathrm{~kg} \mathrm{ha}{ }^{-1}$ da fórmula N-P-K (5-30-15). As parcelas tinham $10 \mathrm{~m}$ de largura por $42 \mathrm{~m}$ de comprimento. Utilizou-se o delineamento experimental de blocos ao acaso em parcelas divididas, com quatro repetições. As parcelas principais foram constituídas pelas culturas de cobertura; as subparcelas, pelos preparos de solo; e as subsubparcelas, pelos dias após a aplicação da ureia.

Em abril de 2005, realizou-se o corte das culturas de coberturas com um triturador de palha e aração com grade aradora nas parcelas destinadas ao sistema de preparo convencional. Sessenta dias após o corte, instalou-se o experimento com feijoeiro comum (Phaseolus vulgaris L.), cv. BRS Valente, conduzido de junho a setembro de 2005, sob irrigação por aspersão. Antes da semeadura aplicou-se, na área total, o herbicida glifosato na dose de $2,4 \mathrm{~kg} \mathrm{ha}^{-1} \mathrm{de}$ i.a. A semeadura do feijoeiro foi feita em 16/6/2005, no espaçamento de $0,45 \mathrm{~m}$ entre linhas e 15 sementes por metro. A adubação de base foi de $400 \mathrm{~kg} \mathrm{ha}^{-1}$, utilizando-se a fórmula N-P-K (4-25-15 + Zn), conforme resultados da análise de solo. Utilizou-se ureia incorporada, na dose de $60 \mathrm{~kg} \mathrm{ha}^{-1}$ de $\mathrm{N}$, a $5 \mathrm{~cm}$ de profundidade, em uma única adubação de cobertura, no início do florescimento.

Para determinação da atividade de urease, coletaram-se amostras de solo aos 3, 6, 8, 10 e 12 dias após a aplicação de ureia no estádio de floração do feijoeiro comum. Em cada subsubparcela, coletaramse amostras compostas de cinco subamostras; após homogeneização, as amostras foram acondicionadas em sacos plásticos, identificadas e armazenadas em câmara fria (em torno de $4{ }^{\circ} \mathrm{C}$ ).

A atividade de urease foi determinada segundo método descrito por Kandeler \& Gerber (1988), com modificações. Amostras compostas de solo fresco (5g) foram misturadas com $20 \mathrm{~mL}$ de solução $75 \mathrm{mmol} \mathrm{L}^{-1}$ de tampão borato, pH 10 e $2,5 \mathrm{~mL}$ de solução $80 \mathrm{mmol} \mathrm{L}^{-1}$ de ureia. Incubaram-se as amostras a $37^{\circ} \mathrm{C}$, sob agitação (200 rpm), durante duas horas. Em seguida, a reação foi interrompida com adição de $30 \mathrm{~mL}$ de solução $1 \mathrm{~mol} \mathrm{~L}^{-1}$ de cloreto de potássio acidificada $\left(0,01 \mathrm{~mol} \mathrm{~L}^{-1} \mathrm{HCl}\right)$, com agitação por $30 \mathrm{~min}$. Alíquotas de 1,4 $\mathrm{mL}$ foram transferidas para microtubos e centrifugadas a $14.000 \mathrm{rpm}$, por $10 \mathrm{~min}$. Após esse tempo, $1 \mathrm{~mL}$ do sobrenadante foi retirado e misturado com $9 \mathrm{~mL}$ de água destilada, $5 \mathrm{~mL}$ de solução básica de salicilato/nitroprussiato de sódio e $2 \mathrm{~mL}$ de solução 0,1 \% de ácido dicloroisocianúrico. Depois de uma hora em repouso, em temperatura ambiente, foi medida a intensidade da cor da solução (formação de um complexo de coloração verde), a $690 \mathrm{~nm}$, em espectrofotômetro UV/Vis. Controles negativos foram feitos, simultaneamente, para verificar a formação de amônia produzida por via não enzimática. $\mathrm{O}$ procedimento foi o mesmo adotado para as amostras, exceto com relação à adição de ureia, que foi feita no final da incubação e imediatamente depois da adição de solução $1 \mathrm{~mol} \mathrm{~L}^{-1} \mathrm{KCl} / \mathrm{HCl}$.

A curva de calibração foi obtida a partir da soluçãopadrão estoque, $1.000 \mathrm{mg} \mathrm{mL}{ }^{-1}$ de $\mathrm{N}-\mathrm{NH}_{4}{ }^{+}$. O conteúdo de $\mathrm{N}-\mathrm{NH}_{4}{ }^{+}$no solo foi calculado pela referência ao gráfico de calibração plotado a partir dos resultados obtidos com as soluções-padrão diluídas, contendo $0 ; 0,125 ; 0,25 ; 0,5 ; 1,0 ; 2,0 ; 3,0 ;$ e $4,0 \mathrm{mg} \mathrm{mL}^{-1}$ 
de $\mathrm{N}-\mathrm{NH}_{4}{ }^{+}$. Todos os tratamentos foram feitos em triplicata, sendo a atividade de urease expressa em $\mathrm{mg} \mathrm{kg}{ }^{-1} \mathrm{~h}^{-1}$ de N-NH${ }_{4}^{+}$no solo.

Para determinação da fertilidade do solo na época da floração do feijoeiro, as amostras de solo foram coletadas na profundidade de $10 \mathrm{~cm}$ e analisadas no Laboratório de Química de Solo da Embrapa Arroz e Feijão, conforme método da Embrapa (1997) (Quadro 1).

Os resultados da atividade da urease foram analisados pelo pacote estatístico SAS (SAS Institute, 1999). Foi feita a análise da variância para avaliar o efeito de plantas de cobertura e preparos de solo, utilizando-se o teste de Tukey $(p<0,05)$ para a diferenciação de médias no caso de significância da análise. Análise de regressão foi efetuada para verificar o efeito das épocas de amostragem do solo.

\section{RESULTADOS E DISCUSSÃO}

A análise de variância mostrou efeito significativo da cobertura vegetal, do sistema de plantio e da época de aplicação da ureia e não significativo da interação entre essas variáveis sobre a atividade de urease no solo (Quadro 2).

Ao considerar as culturas antecedentes ao cultivo do feijoeiro comum, independentemente do sistema de cultivo adotado, observou-se que a palhada do capimmombaça proporcionou maior atividade ureolítica do solo do que as palhadas de sorgo e estilosantes. A atividade de urease observada sobre a palhada de milho em consórcio com braquiária não diferiu daquela das demais palhadas (Figura 1).

O capim-mombaça apresentou maior quantidade de matéria seca da parte aérea $\left(16,1 \mathrm{t} \mathrm{ha}^{-1}\right)$, seguido de braquiária consorciada $\left(10,6 \mathrm{t} \mathrm{ha}^{-1}\right)$, estilosantes (8,7 t ha-1) e sorgo (5,5 t ha-1), na colheita, em 2005. A maior produtividade de matéria seca do capimmombaça refletiu em maior atividade de urease. Essa maior atividade de urease no solo sob cultivo irrigado do feijoeiro comum pode estar relacionada a uma maior disponibilidade de $\mathrm{N}$-orgânico oriundo de exsudados de raízes e dos próprios resíduos radiculares deixados por essa espécie vegetal. Esses resultados concordaram com os obtidos por Rice \& Pancholy (1972), os quais observaram a influência do tipo e da quantidade do material orgânico incorporado ao solo na atividade de urease. A magnitude em que a cultura antecedente contribui para aumentar o metabolismo dos seus resíduos deixados na superfície do solo depende da relação $\mathrm{C} / \mathrm{N}$, composição e quantidade de seus restos culturais (Fageria et al., 1999). O capim-mombaça é uma gramínea e, portanto, possui sistema radicular abundante e elevada rizodeposição, características que auxiliam ativamente na estabilidade dos macroagregados (atributo físico do solo), e também apresenta forte relação com a produção e decomposição

Quadro 1. Características químicas do Latossolo Vermelho distrófico antecedendo ao cultivo do feijoeiro após quatro anos de cultivo com diferentes plantas de cobertura em plantio direto

\begin{tabular}{|c|c|c|c|c|c|c|c|}
\hline Planta de cobertura & $\mathrm{pH}^{(1)}$ & $\mathrm{Ca}^{2+(2)}$ & $\mathrm{Mg}^{2+(2)}$ & $\mathbf{K}^{(3)}$ & $\mathbf{P}^{(3)}$ & $\operatorname{COT}^{(4)}$ & $\mathrm{NT}^{(5)}$ \\
\hline & & \multicolumn{2}{|c|}{$-\mathrm{cmol}_{\mathrm{c}} \mathrm{dm}^{-3}-$} & \multicolumn{2}{|c|}{$-\mathrm{mg} \mathrm{dm}^{-3}$} & $\mathrm{~g} \mathrm{dm} \mathrm{m}^{-3}$ & $\mathrm{~g} \mathrm{~kg}^{-1}$ \\
\hline Capim-mombaça & 5,9 & 3,84 & 1,03 & 169 & 30 & 11,78 & 1,00 \\
\hline Milho em consórcio com braquiária & 5,7 & 2,32 & 0,76 & 137 & 28 & 11,53 & 1,13 \\
\hline Sorgo granífero & 6,0 & 2,45 & 0,86 & 122 & 33 & 11,46 & 1,06 \\
\hline Estilosantes & 5,6 & 1,99 & 0,62 & 142 & 32 & 11,24 & 1,10 \\
\hline
\end{tabular}

${ }^{(1)}$ Relação solo:água 1:2,5. ${ }^{(2)}$ Trocável, Extrator KCL 1 mol L ${ }^{-1} .{ }^{(3)}$ Disponível, Extrator Mehlich-1. ${ }^{(4)}$ Walkley-Black. ${ }^{(5)}$ Kjeldahl.

Quadro 2. Resumo da análise de variância da atividade de urease em Latossolo cultivado com feijoeiro em sucessão a diferentes culturas de cobertura (TRAT), sistemas de preparo (SIS) e épocas de avaliação (EPO)

\begin{tabular}{|c|c|c|c|c|}
\hline Fonte de variação & GL & Quadrado médio & Valor F & $\operatorname{Pr}>\mathbf{F}$ \\
\hline BLOCO & 3 & 14,2208332 & 0,88 & 0,4512 \\
\hline TRAT & 3 & 68,9621947 & 4,29 & 0,0065 \\
\hline SIS & 1 & 217,0138933 & 13,50 & 0,0004 \\
\hline SIS*TRAT & 3 & 7,0541126 & 0,44 & 0,7256 \\
\hline $\mathrm{EPO}$ & 4 & 78,8054775 & 4,90 & 0,0011 \\
\hline EPO*TRAT & 12 & 8,4172909 & 0,52 & 0,8957 \\
\hline $\mathrm{EPO} * \mathrm{SIS}$ & 4 & 9,6142459 & 0,60 & 0,6646 \\
\hline EPO*SIS*TRAT & 12 & 9,6295279 & 0,60 & 0,8391 \\
\hline
\end{tabular}




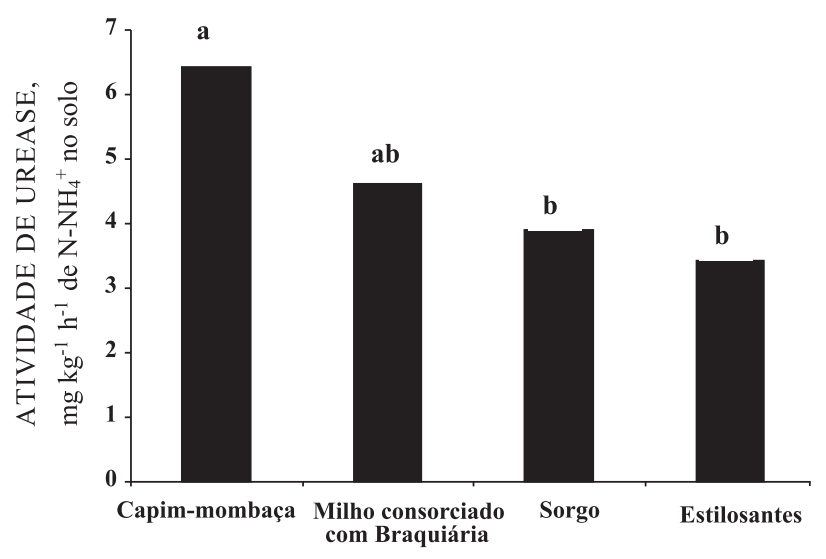

Figura 1. Atividade de urease na camada de $0-10 \mathrm{~cm}$ de solo no estádio de floração da cultivar de feijoeiro BRS Valente em função de plantas de cobertura. Médias seguidas pela mesma letra não diferem entre si pelo teste de Tukey $(p<0,05)$.

dos restos culturais. A relação entre matéria orgânica do solo, estrutura, microrganismos e processos bioquímicos é bastante evidente; enquanto a matéria orgânica e os microrganismos do solo estabilizam a estrutura, uma boa estrutura protege fisicamente a matéria orgânica e os microrganismos do solo, formando um circuito complexo e intimamente ligado entre agregação, microbiota, metabolismo e matéria orgânica (Moreira \& Siqueira, 2006).

Os valores da atividade de urease foram maiores no solo cultivado com gramíneas, como plantas de cobertura, e manejado em sistema plantio direto. Isso se deve, provavelmente, à soma de fatores, como restos vegetais de alta relação $\mathrm{C} / \mathrm{N}$ e ausência de revolvimento das camadas superficiais do solo, o que estimula o aumento da diversidade dos microrganismos heterotróficos e da atividade de enzimas envolvidas na decomposição da matéria orgânica. No caso do solo cultivado com estilosantes, uma espécie de leguminosa, o valor da atividade de urease foi menor em comparação com a atividade em solo cultivado com gramíneas. A baixa relação $\mathrm{C} / \mathrm{N}$ de seus restos vegetais propiciou sua rápida decomposição e, no período de determinação da atividade de urease, início da floração do feijoeiro, sua palhada já não mais contribuiu para o enriquecimento do solo com material orgânico e, consequentemente, aumento da qualidade bioquímica deste. Dessa forma, a intensidade do efeito do material orgânico na atividade da urease dependerá da sua disponibilidade como fonte energética para os microrganismos e também da facilidade de decomposição microbiológica.

Entre os sistemas de preparo do solo foi observada diferença ( $p<0,05$ - Quadro 2) na atividade de urease. No solo sob plantio direto foram observados os maiores valores de atividade de urease, comparativamente ao valor observado no solo sob preparo convencional (Figura 2). Com o decorrer do tempo, em virtude de o
SPD promover incrementos no teor de matéria orgânica, devido à manutenção dos resíduos vegetais na superfície do solo, fica evidente que deve haver correlação positiva entre atividade de urease e teor de matéria orgânica do solo e que diferentes sistemas agrícolas contribuem distintamente com os processos bioquímicos do solo. Nannipieri et al. (1983) também mostraram que a biomassa microbiana e a atividade de urease aumentaram nos solos tratados com resíduos orgânicos. Esses autores sugeriram que a atividade foi influenciada por mecanismos homeostáticos, os quais tendem a manter a composição estável na população microbiana do solo. Como no solo sob preparo convencional existe uma distribuição mais uniforme da matéria orgânica e dos nutrientes no perfil, em virtude da inversão da camada superficial e da incorporação dos resíduos durante a aração, ocorre, em geral, uma taxa mais elevada de decomposição de matéria orgânica e, por conseguinte, há redução na manutenção de complexos enzimas-ácidos húmicos nos coloides orgânicos do solo (Alvarez et al., 1995).

A máxima atividade de urease ocorreu entre o sétimo e o oitavo dia após a aplicação da ureia, independentemente do sistema de preparo e do tipo de planta de cobertura do solo (Figura 3). Assim que a ureia é colocada no solo inicia-se a hidrólise do fertilizante, pela ação da urease. Quanto mais intensa a hidrólise, maior é o potencial de perdas de amônia. Maior atividade da urease é indicação de grande população de microrganismos ureolíticos e, consequentemente, elevadas taxas de perdas de amônia por volatilização. Fatores climáticos, como temperatura (Sengik et al., 2001; Longo \& Melo, 2005), e fatores do solo, como $\mathrm{pH}$, potencial de água, aeração, textura e quantidade de C orgânico (Sengik et al., 2001), são determinantes da atividade da urease.

A determinação da época de amostragem do solo, que forneceu o pico de atividade de urease, é importante porque servirá como referência para

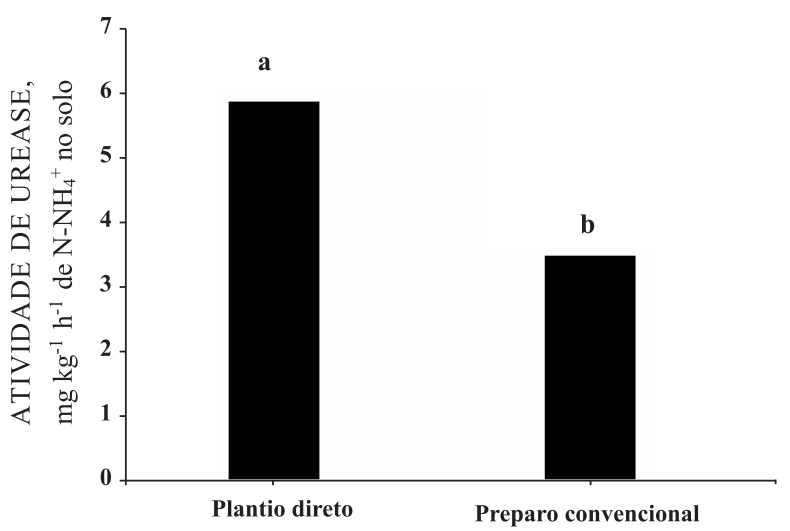

Figura 2. Atividade de urease na camada de $0-10 \mathrm{~cm}$ de solo no estádio de floração da cultivar de feijoeiro BRS Valente em função do sistema de preparo do solo. Médias seguidas por letras diferentes diferem entre si pelo teste de Tukey $(p<0,05)$. 


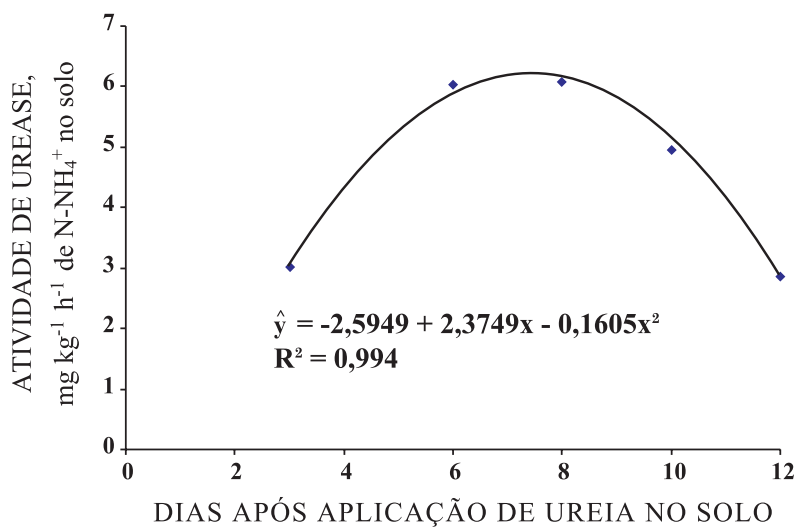

Figura 3. Atividade de urease na camada de $0-10 \mathrm{~cm}$ de solo no estádio de floração da cultivar de feijoeiro BRS Valente em função do número de dias após a aplicação de ureia. Valores médios de quatro plantas de cobertura e dois preparos de solo.

avaliação e monitoramento da qualidade bioquímica do solo em áreas de Cerrado sob cultivo irrigado do feijoeiro comum no inverno, pois, segundo Longo \& Melo (2005), em condições tropicais, pouco se conhece sobre a atividade da urease e os fatores que a alteram.

\section{CONCLUSÕES}

1. A maior atividade de urease no solo ocorreu quando o feijoeiro foi cultivado após capim-mombaça, independentemente do preparo do solo e da época de sua avaliação.

2. A mobilização do solo em cultivo no sistema plantio direto determinou menor atividade de urease, independentemente das espécies de cobertura e das épocas de sua avaliação.

3. O pico de atividade de urease ocorreu entre o sétimo e o oitavo dia após aplicação de ureia, independentemente das espécies de cobertura e do preparo do solo sob cultivo irrigado do feijoeiro comum.

\section{LITERATURA CITADA}

ALVAREZ, R.; DÍAZ, R.A.; BARBERO, N.; SANTANATOGLIA, O.J. \& BLOTTA, R. Soil organic carbon, microbial biomass and $\mathrm{CO}_{2}$ - $\mathrm{C}$ production from three tillage systems. Soil Till. Res., 33:17-28, 1995.

BYRNES, B.H. Liquid fertilizers and nitrogen solutions. In: INTERNATIONAL FERTILIZER DEVELOPMENT CENTER. Fertilizer manual. Alabama, Kluwer Academic, 2000. p.20-44.

D'ANDREA, A.F.; SILVA, M.L.N.; CURI, N. \& GUILHERME, L.R.G. Estoque de carbono e nitrogênio e formas de nitrogênio mineral em um solo submetido a diferentes sistemas de manejo. Pesq. Agropec. Bras., 39:179-186, 2004.
DICK, R.P.; BREAKWELL, D.P. \& TURCO, R.F. Soil enzyme activities and biodiversity as integrative microbiological indicators. In: DORAN, J.W. \& JONES, A.J. Methods for assessing soil quality. Madison, Soil Science Society of America, 1996. p.247-272.

EMPRESA BRASILEIRA DE PESQUISA AGROPECUÁRIA EMBRAPA. Centro Nacional de Pesquisa de Solos. Manual de método de análise de solo. 2.ed. Rio de Janeiro, 1997. 212p. (Embrapa-CNPS. Documentos, 1)

FAGERIA, N.K.; STONE, L.F. \& SANTOS, A.B. Maximização da eficiência de produção das culturas. Brasília, EmbrapaSCT/Embrapa-CNPAF, 1999. 294p.

KANDELER, E. \& GERBER, H. Short-term assay of soil urease activity using colorimetric determination of ammonium. Biol. Fert. Soils, 6:68-72, 1988.

LARA CABEZAS, W.A.R. \& TRIVELIN, P.C.O. Eficiência de um coletor semi-aberto estático na quantificação de $\mathrm{N}$ $\mathrm{NH}_{3}$ volatilizado da uréia aplicada ao solo. R. Bras. Ci. Solo, 14:345-352, 1990.

LONGO, R.M. \& MELO, W.J. Atividade da uréase em Latossolos sob influência da cobertura vegetal e da época de amostragem. R. Bras. Ci. Solo, 29:645-650, 2005.

MOREIRA, F.M.S. \& SIQUEIRA, J.O. Microbiologia e bioquímica do solo. 2.ed. Lavras, Universidade Federal de Lavras, 2006. 729p.

NANNIPIERI P.; MUCCINI, L. \& CIARDI C. Microbial biomass and enzyme activities: Production and persistence. Soil Biol. Biochem, 15:679-685, 1983.

OLIVEIRA, F.H.T.; NOVAIS, R.F.; ALVAREZ V., V.H.; CANTARUTTI, R.B. \& BARROS, N.F. Fertilidade do solo no sistema plantio direto. In: ALVAREZ V., V.H.; SCHAEFER, C.E.G.R.; BARROS, N.F.; MELLO, J.W.V. \& COSTA, L.M., eds. Tópicos em ciência do solo. Viçosa, MG, Sociedade Brasileira de Ciência do Solo, 2002. p.195276.

REYNOLDS, C.M.; WOLF, D.C. \& ARMBRUSTER, J.A. Factors related to urea hydrolysis in soils. Soil Sci. Soc. Am. Proc., 49:104-108, 1987.

RICE, E.L. \& PANCHOLY, S.K. Effect of storage conditions on actives of urease, invertase, amylase and dehydrogenase in soil. Soil Sci. Soc. Am. Proc., 36:536537,1972 .

SANTOS, G.A. \& CAMARGO, F.A.O. Fundamentos da matéria orgânica do solo: Ecossistemas tropicais e subtropicais. Porto Alegre, Gênesis, 1999. 491p.

SAS Institute Inc. SAS/STAT procedure guide for personal computers: version 5. Cary, 1999.

SENGIK, E.; KIEHL, J.C.; SILVA, M.A.G..; PALANGANA, D.C. \& LAWDER, M.R. Perdas de amônia em solo e de resíduos orgânicos autoclavados e tratados com uréia. Acta Sci., 23:1099-1105, 2001.

SILVA, C.C. \& SILVEIRA, P.M. Influência de sistemas agrícolas na resposta do feijoeiro (Phaseolus vulgaris L.) irrigado à adubação nitrogenada em cobertura. Pesq. Agropec. Trop., 30:86-96, 2000. 
SILVA, M.L.N. Solo no contexto ambiental: Textos acadêmicos. Lavras, Universidade Federal de Lavras, 2001. p.109.

TABATABAI, M.A. Soil enzymes. In: WEAVER, R.W.; ANGLE, J.S.; BOTTOMLEY, P.S.; BEZDICEK, D.; SMITH, S.; TABATABAI, A. \& WOLLUM, A., eds. Methods of soil analysis. Microbiological and biochemical properties. Madison, Soil Science Society of America, 1994. v.5. Part 2. p. $775-833$.
TABATABAI, M.A. \& BREMNER, J.M. Assay of urease activity in soils. Soil Biol. Biochem., 4:479-487, 1972.

VICTORIA, R.L.; PICCOLO, M.C. \& VARGAS, A.A.T. O ciclo do nitrogênio. In: CARDOSO, E.J.B.N.; TSAI, S.M. \& NEVES, M.C. Microbiologia do solo. Campinas, Sociedade Brasileira de Ciência do Solo, 1992. p.105-121. 